\title{
Intraoperative Radiotherapy for Locally Advanced Rectal Cancer
}

\author{
Min Kyu Kang, Myung Se Kim, Jae Hwang Kim ${ }^{1}$ \\ Departments of Radiation Oncology and ${ }^{1}$ Surgery, Yeungnam University College of Medicine, Daegu, Korea
}

Purpose: Although intraoperative radiotherapy (IORT) is known to be a method that can reduce local recurrence in locally advanced colorectal cancer, it is not widely used. The aim of this study was to report our experience with IORT for locally advanced rectal cancer.

Methods: From 1991 to 1994, nine patients with locally advanced rectal cancer received IORT. External beam radiotherapy was given postoperatively in five patients and preoperatively in three. Seven patients received chemotherapy. IORT was done with $6-\mathrm{MeV}$ or $9-\mathrm{MeV}$ electrons, and $12 \mathrm{~Gy}$ was irradiated at the tumor bed. The median follow-up period was 84 months (range, 15 to 208 months).

Results: The median age of patients was 51 years (range, 42 to 73 years). All patients had advanced clinical T-stage (cT3/4) cancer. The overall and the disease-free survival rates were $66.7 \%$ and $66.7 \%$ at 5 years, respectively. One patient developed a local recurrence near the anastomosis site, which was out of the IORT field. Four patients died before the last follow-up; three from distant metastasis and one from secondary primary cancer. Adverse effects related to IORT did not occur. Conclusion: Although the number of patients was small in this study, IORT is thought to be safe and effective in reducing local recurrence in locally advanced rectal cancer. However, the role of IORT should be refined in the era of preoperative radio-chemotherapy followed by total mesorectal excision.

Keywords: Rectal cancer; Surgery; Intraoperative radiotherapy; Radiotherapy; Chemotherapy

\section{INTRODUCTION}

The local recurrence rate in locally advanced rectal cancer was reported to be $16-29 \%$ in the past [1]. In order to reduce the recurrence rate in the pelvic cavity, preoperative or postoperative external radiotherapy (45-50 Gy) was executed. However, recent studies have reported that preoperative radio-chemotherapy has more benefits on local control and side effects than postoperative radio-chemotherapy. As a result, preoperative

Received: November 24, 2009 Accepted: June 7, 2010

Correspondence to: Min Kyu Kang, M.D.

Department of Radiation Oncology, Yeungnam University College of Medicine, 317-1 Daemyeong-dong, Nam-gu, Daegu 705-717, Korea

Tel: +82-53-620-3376, Fax: +82-53-624-3599

E-mail: mkkang@ynu.ac.kr

(C) 2010 The Korean Society of Coloproctology

This is an open-access article distributed under the terms of the Creative Commons Attribution NonCommercial License (http://creativecommons.org/licenses/by-nc/3.0) which permits unrestricted noncommercial use, distribution, and reproduction in any medium, provided the original work is properly cited. radio-chemotherapy is being widely used [2-4].

The local recurrence rate in patients treated with a total mesorectal excision is reported to be less than $10 \%$, so the total mesorectal excision is used as the standard method $[1,5]$. However, even in patients treated with a total mesorectal excision, $28 \%$ showed a positive circumferential resection margin (narrower than $1 \mathrm{~mm}$ ). In most research, the local recurrence rate was high in patients with a positive circumferential margin [6]. Cases with a positive circumferential margin after surgery require a high dose greater than 60 Gy [7]. However, delivering a high radiation dose is difficult because of the possibility of side effects on the normal organs including the small intestine and bladder.

On the other hand, intraoperative radiotherapy (IORT) allows precise application of a high radiation dose with minimal exposure of surrounding organs at the time of an operation $[8$, 9]. A high local control rate can be achieved by using IORT, especially in patients with primary or recurrent tumors that are difficult to resect due to severe invasion into adjacent organs 
[10-17]. IORT has been executed at Yeungnam University Medical Center since 1991, and we already reported our early experience [12]. The aim of this study is to investigate the longterm follow-up results of patients with primary locally advanced rectal cancer that were treated with IORT.

\section{METHODS}

\section{Subject group}

From May 1991 to July 1998, 14 colorectal patients were treated with IORT. Among these patients, 10 had primary locally advanced rectal cancer, 2 had primary locally advanced colon cancer, and 2 had recurrent rectal cancer. Subject patients for IORT treatment for primary locally advanced rectal cancer were cases where R0 excision was difficult due to suspicious $\mathrm{T} 4$ lesion or threatened mesorectal fascial invasion, and there were no distant metastasis. Among 10 patients with primary locally advanced rectal cancer, one patient was excluded for the analysis because that patient was lost to follow-up after a palliative abdominoperineal resection. Thus, a total of 9 patients were analyzed in the present study.

\section{Treatment method}

At the beginning of IORT at our institution in 1991, we executed external beam radiotherapy postoperatively after IORT, but since 1992, we have executed external beam radiotherapy preoperatively and IORT has been delivered intraoperatively. Every patient underwent a total mesorectal excision. Whole pelvic radiotherapy was executed in 8 patients. Among them, 5 were irradiated postoperatively with 34.2 to $50.4 \mathrm{~Gy}$ (median, $45 \mathrm{~Gy}$ ) and 3 were irradiated preoperatively with $30 \mathrm{~Gy}$. As chemotherapeutic drugs, a Mayo regimen using 5-fluorouracil was administered in 4 patients, and oral 5-fluorouracil was administered in 3 patients. Two patients had both radiotherapy and chemothearpy before surgery, and 6 patients were administered chemotherapeutics postoperatively. The treatment method for each patient is thoroughly described in Table 1 .

Although methods of IORT executed in our hospital have already been reported [18], a brief summary is follows: The operation and IORT were both executed in a radiotherapy treatment room where the linear accelerator is installed. Locations to be irradiated were determined by the surgeon and radiation oncologist after the primary tumor and lymph node had been removed. The IORT applicator was located in the pelvic cavity, avoiding the small intestine, the ureter, and excised part of the rectum. A dose of $12 \mathrm{~Gy}$ was irradiated by using a $6-\mathrm{MeV}$ or a $9-\mathrm{MeV}$ electron beam.

\section{Follow-up}

Follow-up was done as follows: A physical examination, blood test, and CEA test were done every 3 months for 2 years after the treatment, and after that, they were done every 6 months for the next 3 years. Simple chest radiography and abdomen and pelvis CT scans were done 2 times for the first year and once annually after that. Colonoscopy was done within one year after surgery and every 1-3 years after that. All the patients were followed with a median follow-up of 84 months (range, 15 to 208 months).

\section{Analysis}

Complications related to surgery or radiotherapy were graded based on Common Toxicity Criteria for Adverse Events ver. 3.0 as a standard. The survival period was defined as the time between the date of first treatment and the date of last followup or death. The survival rate was calculated by using the Kaplan-Meier method. The relapse pattern was analyzed by sep-

Table 1. Patient/tumor characteristics and treatment results

\begin{tabular}{|c|c|c|c|c|c|c|c|c|c|c|}
\hline Patients & Sex & Age & $\begin{array}{l}\text { Pathologic } \\
\text { stage }^{\mathrm{a}}\end{array}$ & Treatment & Surgery & IORT (Gy) & $\begin{array}{c}\text { External } \\
\text { radiation (Gy) }\end{array}$ & $\begin{array}{l}\text { Follow-up } \\
\text { periods (mo) }\end{array}$ & Status $^{b}$ & Failures \\
\hline 1 & $\mathrm{~F}$ & 61 & III (C2) & $\mathrm{OP} / \mathrm{IORT} \rightarrow \mathrm{CRCT}$ & APR & 12 & 34.0 & 22 & Dead & Lung \\
\hline 3 & $\mathrm{~F}$ & 55 & III (C2) & $\mathrm{OP} / \mathrm{IORT} \rightarrow \mathrm{RT}$ & LAR & 12 & 45 & 15 & Dead & $\begin{array}{l}\text { Anastomosis } \\
\text { site, Lung }\end{array}$ \\
\hline 4 & $\mathrm{~F}$ & 50 & ॥ (B2) & $\mathrm{OP} / \mathrm{IORT} \rightarrow \mathrm{RT} \rightarrow \mathrm{CT}$ & APR & 12 & 45 & 208 & Alive & - \\
\hline 6 & M & 56 & III (C2) & $\mathrm{RT} \rightarrow \mathrm{OP} / \mathrm{IORT} \rightarrow \mathrm{CT}$ & APR & 12 & 30.6 & 203 & Alive & - \\
\hline 7 & M & 42 & III (C1) & $\mathrm{CRCT} \rightarrow \mathrm{OP} / \mathrm{IORT} \rightarrow \mathrm{CT}$ & ULAR & 12 & 30.4 & 189 & Alive & - \\
\hline 8 & M & 51 & I (B1) & $\mathrm{CRCT} \rightarrow \mathrm{OP} / \mathrm{IORT}$ & APR & 12 & 30.6 & 84 & Dead & - \\
\hline 9 & $\mathrm{~F}$ & 44 & \|l (B2) & $\mathrm{OP} / \mathrm{IORT} \rightarrow \mathrm{CT}$ & LAR & 12 & - & 76 & Alive & - \\
\hline
\end{tabular}

APR, abdominoperineal resection; CRCT, concurrent radio-chemotherapy; CT, chemotherapy; IORT, intraoperative radiotherapy; LAR, low anterior resection; OP, operation; $\mathrm{RT}$, radiotherapy; ULAR, ultra-low anterior resection.

aAJCC 2002 TNM staging (modified Astler-Coller stage); 'Patients' survival status at the last follow-up. Patients 1-3 died of systemic failure, and patient 8 died of gallbladder cancer as a secondary malignancy. 
arating local and distant relapses. Intra-pelvic relapse was defined as a local relapse, and extra-pelvic cavity relapse as distant metastasis.

\section{RESULTS}

\section{Patient characteristics}

Among 9 patients, 4 were males, and the age range of all patients was 42-73 years old (median, 51 years old). The tumor histology was an adenocarcinoma in all patients. The stages of the tumors for all patients who had immediate surgical treatment after diagnosis were TNM stage II (4 patients) and III (2 patients). Patients who underwent preoperative radiotherapy had ypI (1 patient) and ypIII stage (2 patients). The location of the tumor was $1-9 \mathrm{~cm}$ (median, $5 \mathrm{~cm}$ ) from the anal verge. Four patients underwent an abdominoperineal resection, and 5 patients underwent a low anterior resection. In all patients, proximal and distal margins were free for tumors, but in three patients, circumferential margins were positive for tumors (within $1 \mathrm{~mm}$ ).

\section{Side effects}

Grade III/IV toxicity occurred in one patient, who had surgical treatment for ileus and anastomosis stenosis. However, neither ureteral stricture nor neuropathy was found in any patients.

\section{Relapse patterns}

Relapse occurred in 3 patients, and the 5-year disease-free survival rate was $66.7 \%$ (Fig. 1). The most common relapse was distant metastasis, which was discovered 7-17 months after surgery. Two patients had lung metastasis, and 1 patient had liver metastasis. One patient had a local relapse in the proximal side of the anastomosis site, along with a distant metastasis that occurred 7 months after the surgery. However, no relapses were

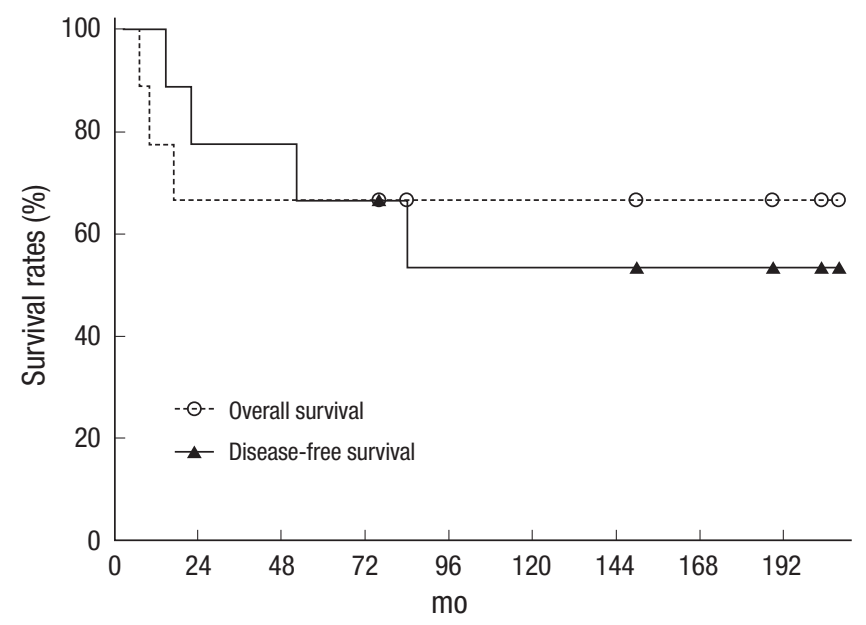

Fig. 1. Survival rates of 9 patients who were treated with intraoperative radiotherapy. noted in the IORT field.

\section{Survival rate}

A total of 4 patients died before the last follow-up. Three patients died of distant metastasis and progress of the disease. The other patient had gallbladder cancer that occurred 74 months after surgery and died 8 months later. The 5 -year and the 10 -year overall survival rates were $66.7 \%$ and $53.3 \%$, respectively (Fig. 1).

\section{DISCUSSION}

Although the number of patients who underwent IORT was small, there were no IORT-related side effects or relapse in the IORT field. The local relapse rate for cT3/4 rectal cancer was $2-13 \%$ in other research $[10,11,13-18]$. In cases where complete excision was possible, the local relapse rate was $2-6 \%$, and relapses occurred mostly away from the IORT irradiation site. Common side effects that occur if IORT is executed inside the pelvic cavity are neuropathy and ureteral stricture. Neuropathy is mostly related with IORT dose and is rare at a dose of $12 \mathrm{~Gy}$, which was the dose used in the current study. One patient out of 29 who underwent preoperative or postoperative external radiotherapy (45-55 Gy) and IORT (7.5-12.5 Gy) was reported to have grade-II neuropathy $[10,19]$. The ureter has more resistance to radiation than the peripheral nerve, and in animal experiments, fibrosis or stricture occurred when a radiation dose greater than 30 Gy was delivered [19]. However, ureteral stricture can be treated with a stent, so the ureter near the tumor does not have to be displaced from the irradiation field. Accordingly, adding IORT of 12 Gy to external radiotherapy of 45-50 Gy is thought to be safe for normal tissue inside the pelvic cavity.

A positive resection margin or the presence of a residual tumor is an indication for IORT because of the high rate of local relapse. The Mayo clinic uses a dose of 7.5-10 Gy when the resection margin is negative, 10-12.5 Gy when the resection margin is microscopically positive, 15 Gy when the residual tumor is less than or equal to $2 \mathrm{~cm}, 17.5-20$ Gy when the residual tumor is greater than $2 \mathrm{~cm}$, and $45-55 \mathrm{~Gy}$ as preoperative or postoperative external radiotherapy [10]. There was difference in the local relapse rate depending on the extent of the residual tumor; $5 \%$ for microscopically positive residual tumors and $25 \%$ for gross residual tumors. And there were no relapses within the IORT field, except 1 patient where the tumor was not completely excised. On the other hand, patients who had incomplete removal and underwent only external radiotherapy had a high local relapse rate of $76 \%$ in the same institute [20].

Preoperative radio-chemotherapy is used to increase the complete excision rate in patients with locally advanced rectal cancer. According to following studies, additional IORT after suc- 
cessful radical excision following preoperative radiotherapy helps increase local control $[11,13]$. Massachusetts General Hospital executed 50.4 Gy preoperative radiotherapy and 10 to 15 Gy IORT (mostly 15 Gy) in unresectable locally advanced rectal cancer cases [11]. The 5-year local control rate of 22 patients who had IORT after complete excision was $88 \%$. On the other hand, the 5-year local control rate of 13 patients who did not have IORT because of not having adhesion and resection margin greater than $5 \mathrm{~mm}$ was $71 \%$. Ratto et al. [13] executed preoperative radio-chemotherapy of $45 \mathrm{~Gy}$ in cT4 and cN3 patients (40 cT4 patients and 3 cT3 patients) and a total mesorectal excision. Radical excision was possible in $88 \%$ of the patients, and IORT (10-15 Gy) was done in 19 patients. The 5 -year local control rates of the IORT-irradiated group and the non-IORT-irradiated group were $90.9 \%$ and $56.7 \%$, respectively. There were no relapses within the IORT field.

Among studies on locally advanced rectal cancer, there were differences between studies where IORT was executed after preoperative radio-chemotherapy [14-16] and studies where IORT was not executed (phase III study) [4]. The local recurrence rate in the IORT group was lower than that in the nonIORT group (preoperative radio-chemotherapy only group) $(2-3 \%$ vs. $6 \%)$ in spite of the higher number of cT4 patients and the lower rate of total mesorectal excision in the IORT group. Although we cannot directly compare the results from studies with different subject patients, according to the facts above, preoperative radio-chemotherapy followed by IORT seems to be able to further increase the local control rate. However, a total mesorectal excision is being used as the standard, so it is difficult to say that IORT following radio-chemotherapy is necessarily beneficial.

However, according to the meta-analysis results for the relationship between the circumferential resection margin and the local relapse rate, patients needing IORT can be sorted out [6]. In this study, in cases of positive circumferential resection margins, the relative risks of local relapse in the group that underwent preoperative radiotherapy and in the group that did not were 6.3 (95\% confidence interval [CI], 3.7 to 16.7 ) and 2.0 ( $95 \%$ CI, 1.4 to 2.9), respectively. Because of the high local relapse rate in patients with positive resection margins, additional radiotherapy after surgery might be helpful. However, using external radiotherapy is limited due to the normal tissue tolerance, whereas IORT can be used safely and selectively. The sensitivity and positive predictive value of magnetic resonance imaging (MRI) on mesorectal fascia involvement in rectal cancer treated with preoperative radiotherapy are $75-100 \%$ and $57-92 \%$, respectively $[21,22]$. Although more studies are needed, MRI could be a help in selecting patients for whom increased local control rate can be achieved through the use of IORT.

According to the long-term follow-up results from a small group of patients with locally advanced rectal cancer who was treated with IORT, local relapse was not observed in the IORT field. Although there have been no case-control studies with large subject groups, based on our experience and on the results of other studies, adding IORT to preoperative or postoperative radio-chemotherapy will increase the local control rate without major complications. However, more studies are needed to determine the effects of IORT on patients with resectable locally advanced rectal cancer who are treated with preoperative radio-chemotherapy and a total mesorectal excision.

\section{CONFLICT OF INTEREST}

No potential conflict of interest relevant to this article was reported.

\section{REFERENCES}

1. McCall JL, Cox MR, Wattchow DA. Analysis of local recurrence rates after surgery alone for rectal cancer. Int J Colorectal Dis 1995;10:126-32.

2. Colorectal Cancer Collaborative Group. Adjuvant radiotherapy for rectal cancer: a systematic overview of 8,507 patients from 22 randomised trials. Lancet 2001;358:1291-304.

3. Krook JE, Moertel CG, Gunderson LL, Wieand HS, Collins RT, Beart RW, et a. Effective surgical adjuvant therapy for high-risk rectal carcinoma. N Engl J Med 1991;324:709-15.

4. Sauer R, Becker H, Hohenberger W, Rodel C, Wittekind C, Fietkau $\mathrm{R}$, et al. Preoperative versus postoperative chemoradiotherapy for rectal cancer. N Engl J Med 2004;351:1731-40.

5. Wiig JN, Carlsen E, Soreide O. Mesorectal excision for rectal cancer: a view from Europe. Semin Surg Oncol 1998;15:78-86.

6. Nagtegaal ID, Quirke P. What is the role for the circumferential margin in the modern treatment of rectal cancer? J Clin Oncol 2008;26:303-12.

7. Allee PE, Tepper JE, Gunderson LL, Munzenrider JE. Postoperative radiation therapy for incompletely resected colorectal carcinoma. Int J Radiat Oncol Biol Phys 1989;17:1171-6.

8. Calvo FA, Meirino RM, Orecchia R. Intraoperative radiation therapy first part: rationale and techniques. Crit Rev Oncol Hematol 2006;59:106-15.

9. Willett CG, Czito BG, Tyler DS. Intraoperative radiation therapy. J Clin Oncol 2007;25:971-7.

10. Gunderson LL, Nelson H, Martenson JA, Cha S, Haddock M, Devine R, et al. Locally advanced primary colorectal cancer: intraoperative electron and external beam irradiation $+/$ - 5-FU. Int J Radiat Oncol Biol Phys 1997;37:601-14.

11. Willett CG, Shellito PC, Tepper JE, Eliseo R, Convery K, Wood WC. Intraoperative electron beam radiation therapy for primary locally advanced rectal and rectosigmoid carcinoma. J Clin Oncol 1991;9:843-9.

12. Kim MS, Kim SK, Kim JH, Kwan KB, Kim HD. Intraoperative radiotherapy (IORT) for locally advanced colorectal cancer. J Korean Soc Ther Radiol 1991;9:265-70. 
13. Ratto C, Valentini V, Morganti AG, Barbaro B, Coco C, Sofo L, et al. Combined-modality therapy in locally advanced primary rectal cancer. Dis Colon Rectum 2003;46:59-67.

14. Calvo FA, Gomez-Espi M, Diaz-Gonzalez JA, Alvarado A, Cantalapiedra R, Marcos P, et al. Intraoperative presacral electron boost following preoperative chemoradiation in $\mathrm{T} 3-4 \mathrm{Nx}$ rectal cancer: initial local effects and clinical outcome analysis. Radiother Oncol 2002;62:201-6.

15. Sadahiro S, Suzuki T, Ishikawa K, Fukasawa M, Saguchi T, Yasuda $\mathrm{S}$, et al. Preoperative radio/chemo-radiotherapy in combination with intraoperative radiotherapy for T3-4Nx rectal cancer. Eur J Surg Oncol 2004;30:750-8.

16. Eble MJ, Lehnert T, Herfarth C, Wannenmacher M. IORT as adjuvant treatment in primary rectal carcinomas: multi-modality treatment. Front Radiat Ther Oncol 1997;31:200-3.

17. Mannaerts GH, Martijn H, Crommelin MA, Dries W, Repelaer van Driel OJ, Rutten HJ. Feasibility and first results of multimodality treatment, combining EBRT, extensive surgery, and IOERT in locally advanced primary rectal cancer. Int J Radiat Oncol Biol Phys 2000;47:425-33.

18. Huber FT, Stepan R, Zimmermann F, Fink U, Molls M, Siewert
JR. Locally advanced rectal cancer: resection and intraoperative radiotherapy using the flab method combined with preoperative or postoperative radiochemotherapy. Dis Colon Rectum 1996;39: 774-9.

19. Sindelar WF, Kinsella TJ. Normal tissue tolerance to intraoperative radiotherapy. Surg Oncol Clin N Am 2003;12:925-42.

20. Schild SE, Martenson JA Jr, Gunderson LL, Dozois RR. Long-term survival and patterns of failure after postoperative radiation therapy for subtotally resected rectal adenocarcinoma. Int J Radiat Oncol Biol Phys 1989;16:459-63.

21. Vliegen RF, Beets GL, Lammering G, Dresen RC, Rutten HJ, Kessels AG, et al. Mesorectal fascia invasion after neoadjuvant chemotherapy and radiation therapy for locally advanced rectal cancer: accuracy of MR imaging for prediction. Radiology 2008;246: 454-62.

22. Kim SH, Lee JM, Park HS, Eun HW, Han JK, Choi BI. Accuracy of MRI for predicting the circumferential resection margin, mesorectal fascia invasion, and tumor response to neoadjuvant chemoradiotherapy for locally advanced rectal cancer. J Magn Reson Imaging 2009;29:1093-101. 